\title{
Lung involvement in Sjögren's syndrome: a comparison between patients with primary and with secondary syndrome
}

\author{
C VITALI, ${ }^{1}$ A TAVONI, ${ }^{1}$ G VIEGI, ${ }^{3}$ E BEGLIOMINI, ${ }^{3}$ A AGNesi, ${ }^{2}$ AND \\ S BOMBARDIERI ${ }^{1}$
}

From the ${ }^{1}$ Rheumatic Disease Unit and ${ }^{2}$ Otorhinolaryngology Department, University of Pisa, and ${ }^{3}$ Pulmonary Unit, CNR Clinical Physiology Laboratory, Pisa, Italy

SUMMARY Lung function was assessed in 20 patients with primary Sjögren's syndrome (SS) and in a group of patients with SS associated with a variety of connective tissue diseases. Signs of small airway disease and of altered diffusion capacity, together with chest $x$-ray features of mild interstitial involvement, were the most common findings in primary SS. On the whole, lung involvement was more frequent and severe in patients with the secondary form of the syndrome. In both primary and secondary SS lung function changes did not correlate with the other clinical and serological parameters, except for a more severe impairment of diffusion capacity in patients with Raynaud's phenomenon.

Key words: lung volume measurements, airway obstruction, pulmonary diffusing capacity, pulmonary fibrosis, Raynaud's disease, antinuclear antibodies, immune complex disease.

Sjögren's syndrome (sicca syndrome) (SS) is an autoimmune disease characterised by exocrine gland involvement, particularly the lacrimal and salivary glands, sometimes associated with connective tissue diseases or immunological disorders. ${ }^{1}$ The presence of pulmonary involvement in SS has already been described, ${ }^{2}$ and a number of lung function studies have shown different patterns of respiratory impairment. ${ }^{2-6}$ These studies however, employed disparate techniques ${ }^{34}$ and/or took into account only isolated parameters. ${ }^{46}$ Furthermore, in many instances no distinction was made between patients with the primary or the secondary form of $\mathrm{SS}^{2-5}$ and smoking was not explicitly considered. ${ }^{2-6}$ It is not surprising, therefore, that most of these studies have yielded different and often conflicting results. ${ }^{236}$ To verify the prevalence and nature of lung involvement in SS we evaluated lung function, arterial blood gases, and radiographic findings in two comparable, unselected groups of non-smokers with primary or secondary SS.

Accepted for publication 21 January 1985.

Correspondence to Dr Claudio Vitali, Servizio di Reumatologia, Istituto di Patologia Medica I, Università di Pisa, via Roma 2, 56100 Pisa, Italy.

\section{Materials and methods}

\section{PATIENTS}

Forty patients with SS (all non-smoking women, aged 21-75 years, mean $45 \cdot 2$ years), referred to the Rheumatic Disease Unit of the University of Pisa between 1977 and 1984 were studied. Of these, 20 (aged 21-67 years, mean $44 \cdot 3$ years) had primary SS and 20 (aged 22-75 years, mean 45.0 years) had secondary SS (seven progressive systemic sclerosis (PSS), six rheumatoid arthritis (RA), three systemic lupus erythematosus (SLE), two essential mixed cryoglobulinaemia (EMC), and two mixed connective tissue disease (MCTD)). In both groups the diagnosis of SS was suspected from the presence of xerostomia, xerophthalmia, and parotid swelling, and established when keratoconjunctivitis sicca was shown (positive Schirmer's test or slit lamp examination after rose bengal staining, or both), and when salivary gland involvement was confirmed by sialography or lip biopsy, or both. ${ }^{1}$

In the secondary SS group the diagnosis of the associated diseases was made on the basis of well established criteria for RA, ${ }^{7}$ SLE,${ }^{8}$ PSS, ${ }^{9}$ MCTD,${ }^{10}$ and EMC. ${ }^{11}$

None of the patients studied had signs or symp- 
toms of acute respiratory disease when their lung function was investigated or previous important bronchopulmonary disorders of other aetiology.

SEROLOGICAL STUDIES

Blood samples for serological studies were obtained from all patients at the time of lung function evaluation.

The determination of cryoglobulins was made as previously described. ${ }^{11}$ Circulating immune complexes (CIC) were measured by a competitive enzyme immunoassay previously developed in our laboratory. ${ }^{12}$ Values above $35 \%$ of inhibition were considered abnormal. $\mathrm{CH}_{50}$ levels were determined by the method of Kent and Fife ${ }^{13}$ (normal values 160-220 U/ml) and antinuclear antibodies (ANA) by indirect immunofluorescence, with mouse liver as the substrate. Anti-extractable nuclear antigen (anti-ENA) antibodies were detected by counterimmunoelectrophoresis according to the method of Bunn et al. ${ }^{14} \mathrm{~A}$ commercial source of rabbit thymus (Pel-Freez Biologicals Inc., Rogers, Arkansas) and human spleen extract ${ }^{15}$ was available. Reference anti-SSA (Ro), anti-SSB (La), anti-RNP, and antiSm sera were kindly provided by Dr M Reichlin and Dr G R V Hughes.

\section{LUNG FUNCTION STUDIES}

On the same morning, the following measurements were made in each patient: (a) static lung volumes: total lung capacity (TLC), residual volume (RV), the $\mathbf{R V} / \mathrm{TLC}$ ratio, vital capacity (VC) (obtained by a computerised high power pulmonary desk system); (b) forced vital capacity (FVC) and derived indexes, according to the protocol of the CNR special project on preventive medicine (same apparatus) (unpublished data). For this study, the following parameters were recorded: maximal expiratory volume in the first second (FEV1), the FEV1/VC ratio, forced expiratory flow between 75 and $85 \%$ of FVC (FEF 75-85), and maximal expiratory flow at 75\% of FVC (MEF 75); (c) diffusing capacity of the lung for carbon monoxide (CO) in a single breath (DLCO-SB), ${ }^{16}$ which divided by alveolar volume yields the $\mathrm{CO}$ coefficient of transfer $(\mathrm{KCO})^{17}$ (Morgan Resparameter MK4); (d) the diffusing capacity of $\mathrm{CO}$ at the steady state: total (DLCOSS2), ${ }^{18}$ and per unit of minute ventilation (DLCO$\mathrm{SS} 2 / \mathrm{Ve}$ ); fractional uptakes of $\mathrm{CO}$ (DuCO, DuaCO) were also calculated; ${ }^{19}$ and (e) arterial gases $\left(\mathrm{Po}_{2}\right.$ and $\left.\mathrm{PcO}_{2}\right)$ at rest, on a blood sample withdrawn from the radial artery (IL model 213).

Lung function parameters were expressed as percentages of predicted values; the latter were derived from Goldman ${ }^{20}$ for static spirometry, from
Morris $^{21}$ and Knudson ${ }^{22}$ for flow-volume curves, from Cotes ${ }^{17}$ and Van Ganse ${ }^{23}$ for DLCO-SB and $\mathrm{KCO}$, respectively, from Bates $^{18}$ and from $\vec{\omega}$ Mastrangelo $^{19}$ for DLCO-SS2 and DuCO-DuaCO, respectively.

\section{CHEST ROENTGENOGRAMS}

Chest $x$-ray examination was carried out in two projections: posteroanterior and lateral. Teleradio- $\infty$ grams were all evaluated by the same physician, $\vec{\circ}$ with a simple scoring system: $0=$ no alterations; $\overrightarrow{\vec{\omega}}$ $1=$ hilar blurring or bibasilar accentuation of in- $\omega$ terstitial network; 2 = diffuse interstitial thickening; $3=$ presence of micronodular or linear shadows and/or ill defined cardiac borders.

STATISTICAL ANALYSIS

Mean values were compared by the Student's $t$ test and the $\chi^{2}$ test with Yates's correction was used to compare percentages. Simple and multiple correlations between the serological and the lung function parameters were also sought.

\section{Results}

Only a few of our patients had bronchopulmonary symptoms (see footnotes to Tables 1 and 2). Among the patients with primary SS $65 \%$ had evidence of extraglandular organ involvement. In one of these (case No. 15) a lymphosarcoma became evident a few months before the study (Table 1 ).

As far as serological findings are concerned rheumatoid factor (RF) and ANA were largely present in both primary and secondary SS. AntiENA antibodies were found in one half of the patients in both groups; however, although antiSSA and anti-SSB antibodies accounted for nearly all the specificities observed in primary SS patients, anti-RNP and anti-SSB were the most common antibodies in secondary SS (Tables 1 and 2).

The lung function parameters most frequently impaired in patients with primary SS (Table 3 ) were MEF 75, KCO, and DLCO-SS2 (55\% of patients), N and DuCO and DuaCO (45\% of patients). In contrast, lung volumes were only rarely affected in $\triangle$ these patients. Patients with secondary SS showed a $\omega$ larger spectrum of lung function abnormalities. Moreover, for nearly all the parameters considered $Q$ an impairment was more frequent in this group than in the patients with the sicca syndrome alone, and this difference reached statistical significance for DLCO-SB (Table 3).

Finally, when the mean values of the various parameters in the two groups were compared (Table 4) some lung function indexes (FEV1, MEF 75, FEF 75-85) and $\mathrm{PO}_{2}$ were significantly lower in the

\section{.}




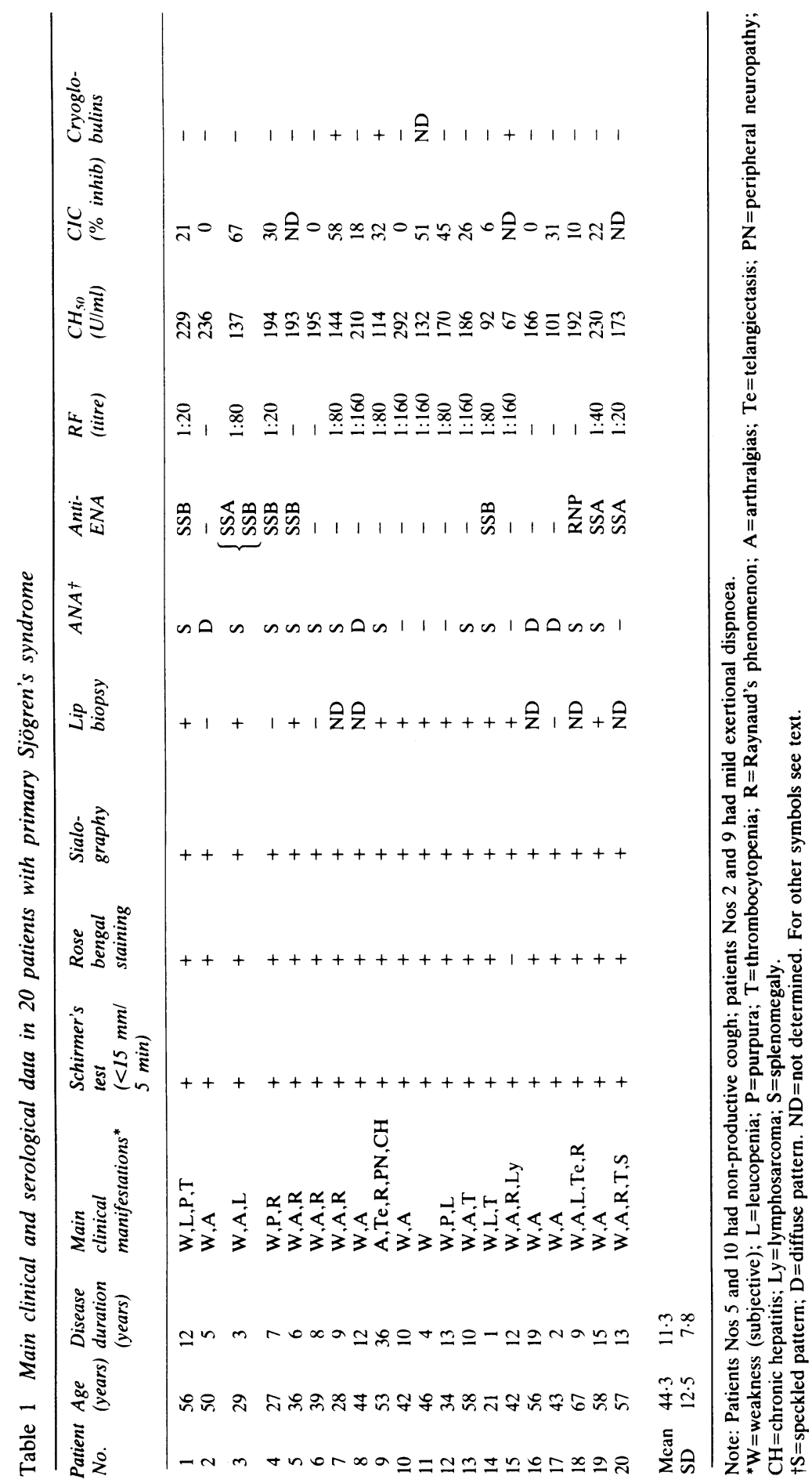




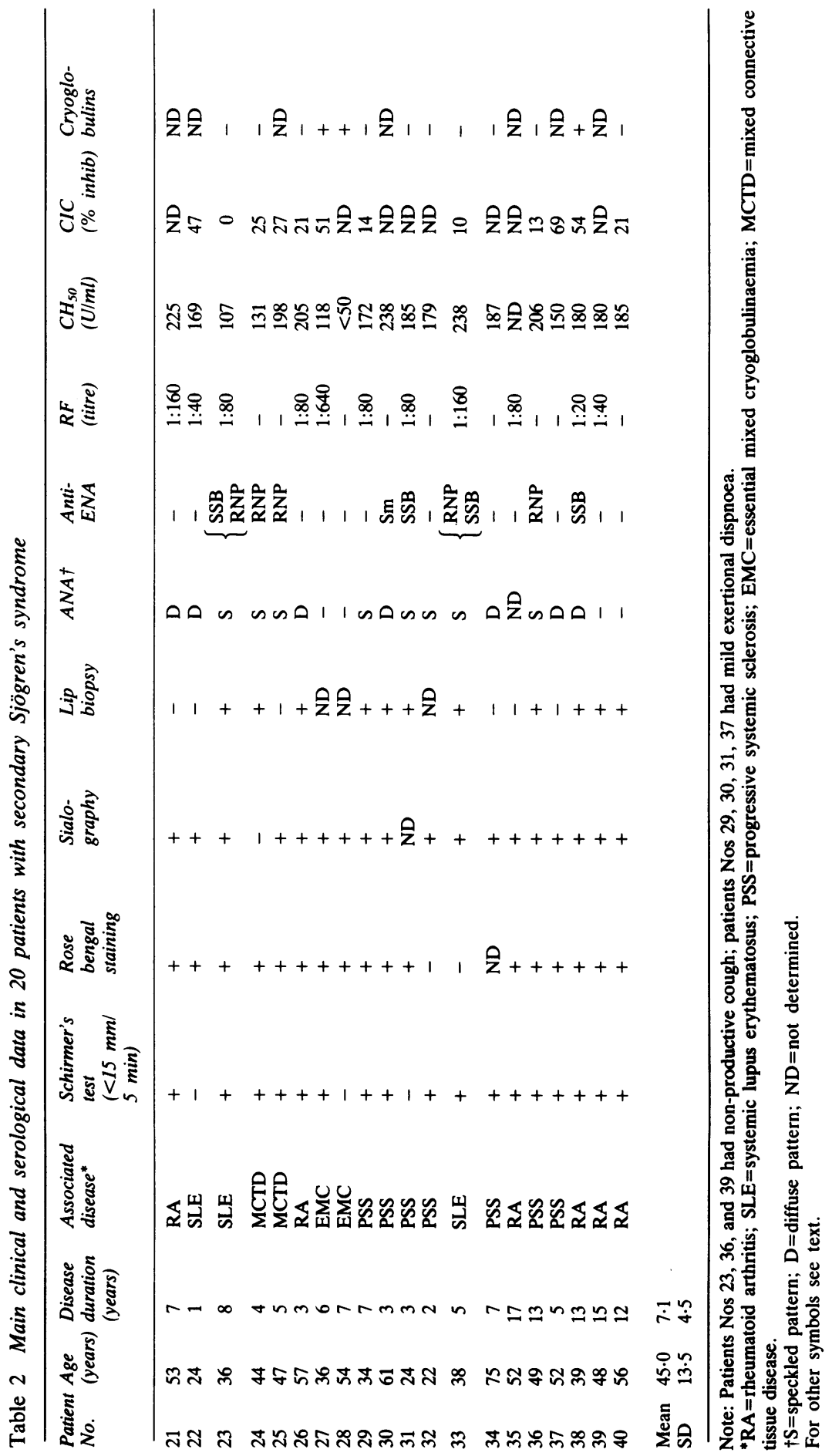


secondary syndrome than in the primary SS group. This finding was confirmed by chest $x$-ray evaluation: radiographic abnormalities were significantly more frequent (Table 3) and severe (Table 4) in patients with associated diseases than in those with primary SS.

Respiratory functional indexes did not differ on the average between patients with or without parotid swelling, ANA or anti-ENA antibodies, and $\mathrm{RF}$, in the whole population of SS patients or in the two subgroups. None of the lung function parameters was significantly correlated with RF titre, gammaglobulins, $\mathrm{CH}_{50}$, or $\mathrm{CIC}$ levels, in both single and multiple regression analysis, either in the whole group of patients or in the primary or secondary group. However, patients in both groups with Raynaud's phenomenon showed significantly lower DLCO-SB values as compared with those without this clinical feature (mean $\pm \mathrm{SD}$ : 77.2 $\pm 17.6 v$ $84.7 \pm 14.6$ as percentage of the predicted values, respectively; $t=2.077, \mathrm{p}<0.05$ ).

\section{Discussion}

In this study we show that lung involvement can occur in the course of SS. In our patients lung involvement was characterised by the impairment of the tests usually considered to be indicative of small airway disease (FEF 75-85 and MEF 75), ${ }^{24}$ or of the diffusion capacity parameters (DLCO, KCO, DuCO, DuaCO), or both. Finally, interstitial lung involvement was evident in some of our patients on chest $x$-ray examination. On the whole both functional and radiographic abnormalities were less frequent and severe in patients with primary SS than in those with SS associated with other connective tissue diseases. These results are only partially in agreement with previous reports. An impaired diffusion capacity has already been found in a large percentage of 46 patients with primary SS. ${ }^{6} \mathrm{Im}$ paired DLCO and restrictive ventilatory defects were also observed by Strimlan et al. ${ }^{2}$ and by Fairfax et al. ${ }^{4}$ in two series of 18 and 17 patients with SS. In contrast, mostly obstructive defects were observed by Segal et al., ${ }^{5}$ and Newball and Brahim, ${ }^{3}$ who studied relatively small numbers of patients with SS. In none of these reports, however, did patients with primary SS account for more than $50 \%$ of the population studied. Furthermore, the presence of small airway disease was not directly shown in these studies, although it could be suspected on the basis of some lung function and/or histological findings. ${ }^{34}$

The lower prevalence of obstructive or restrictive defects in our patients with primary SS can be explained in two ways: first, patients with bronchopulmonary disorders, such as pleurisy, bronchitis, or pneumonitis, not necessarily related to SS, and smokers were rigidly excluded; secondly patients with primary SS were separated from those with an associated connective tissue disease, because it is known that a more or less severe pulmonary involvement is often present in the course of RA, ${ }^{25}$ SLE ${ }^{26}$ PSS,${ }^{27}$ MCTD,${ }^{10}$ and EMC. ${ }^{11}$ This may also explain the more frequent and severe lung impairment observed in our patients with secondary SS.

No pathological data are available, and therefore the pathogenesis of the lung lesions observed in our patients with primary SS remains largely speculative. It has been suggested that the sicca syndrome may favour the occurrence of a chronic inflamma-

Table 3 Lung involvement in Sjögren's syndrome: a comparison of patients with primary and secondary syndrome

\begin{tabular}{|c|c|c|c|c|c|c|c|}
\hline \multirow[t]{2}{*}{ Parameter } & \multirow{2}{*}{$\begin{array}{l}\text { Pathological } \\
\text { limits } \\
\text { (\% of predicted) }\end{array}$} & \multicolumn{2}{|c|}{$\begin{array}{l}\text { Primary SS } \\
\text { pathological cases }\end{array}$} & \multicolumn{2}{|c|}{$\begin{array}{l}\text { Secondary SS } \\
\text { pathological cases }\end{array}$} & \multirow[t]{2}{*}{$\chi^{2}$ (Yates) } & \multirow[t]{2}{*}{$p$} \\
\hline & & No & $\%$ & No & $\%$ & & \\
\hline TLC & $<80>120$ & $0 / 20$ & 0 & $2 / 19$ & $10 \cdot 5$ & 0.583 & NS $\dagger$ \\
\hline RV & $<80>120$ & $5 / 20$ & 25 & $5 / 19$ & $26 \cdot 3$ & 0.074 & NS \\
\hline FEV1 & $<82^{*}$ & $1 / 20$ & 5 & $5 / 19$ & $26 \cdot 3$ & 1.960 & NS \\
\hline MEF 75 & $<52^{*}$ & $11 / 20$ & 55 & $14 / 19$ & $73 \cdot 7$ & 0.778 & NS \\
\hline FEF $75-85$ & $<47^{*}$ & $3 / 20$ & 15 & $9 / 19$ & $47 \cdot 4$ & 3.393 & NS \\
\hline DLCO-SB & $<80$ & $4 / 20$ & 20 & $11 / 20$ & 55 & $3 \cdot 840$ & $<0.05$ \\
\hline $\mathrm{KCO}$ & $<80$ & $11 / 20$ & 55 & $11 / 20$ & 55 & $0 \cdot 101$ & NS \\
\hline DLCO-SS2 & $<80$ & $11 / 20$ & 55 & $16 / 20$ & 80 & $1 \cdot 823$ & NS \\
\hline DuCO & $<80$ & $9 / 20$ & 45 & $12 / 20$ & 60 & 0.401 & NS \\
\hline DuaCO & $<80^{\circ}$ & $9 / 20$ & 45 & $7 / 20$ & 35 & $0 \cdot 104$ & NS \\
\hline Chest $x$-ray score & $\geqslant 1$ & $5 / 18$ & $27 \cdot 8$ & $15 / 20$ & 75 & $6 \cdot 685$ & $<0.01$ \\
\hline
\end{tabular}

*These figures are the normal 95th percentile, derived from an analysis of the data collected in an epidemiological survey in the North of Italy (unpublished data). 


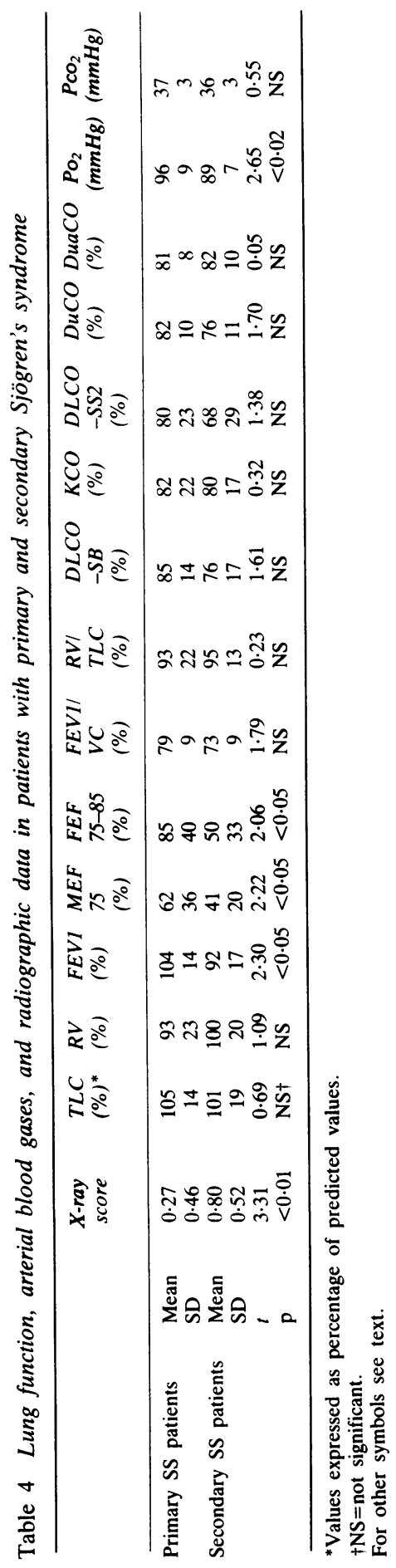

tory process in the bronchial walls and glands and this could cause an obstructive syndrome. ${ }^{2}$ How-? ever, signs and symptoms of chronic bronchial $\overrightarrow{\vec{F}}$ damage were very rarely encountered in our pa- $-\overrightarrow{0}$ tients. On the other hand, the presence of small등 airway disease could be due to interstitial involve- $\overline{\bar{c}}$ ment, in a way similar to that suggested for other $\overrightarrow{\mathrm{d}}$ systemic disorders. ${ }^{28}$ This hypothesis would be supported in our study by the radiographic findings ${ }^{\infty}$ and by the diffusion capacity abnormalities. The $\vec{\circ}$ pathogenesis of the interstitial lung damage found in $\overrightarrow{\vec{\omega}}$ connective tissue diseases is still debated, but $\sigma_{\sigma}^{\omega}$ experimental ${ }^{29}$ and clinical ${ }^{30}$ studies support the role@ of immune complex deposition with subsequent $\stackrel{\rho}{-}$ local activation of an inflammatory response. CIC $\stackrel{\vec{\perp}}{A}$ are frequently encountered in the course of SS, and. they are commonly believed to be responsible forct some of the systemic features of this disorder. ${ }^{31} \mathrm{In}_{\circ}$ this study and a previous one ${ }^{4}$ CIC levels failed to correlate with lung function impairment but this $\vec{C}$ does not necessarily rule out this hypothesis. It is known that CIC levels may change on follow up, ${ }^{32}+$ whereas most of the lung function parameters areos the result of a pathological and functional damage already established in these diseases. On the othero hand, the lack of correlation between clinicals features and CIC levels might be due to the fact thato none of the methods employed for immune complex\% detection is able to determine all the immune complexes, ${ }^{33}$ and that multiple types of complexes $\overrightarrow{{ }_{0}}$ are likely to be present in the same serum. ${ }^{32}$

Finally, an increased vasospasm of lung vessels? ('Raynaud's phenomenon of the lung') has been? observed in patients with certain connective tissuea diseases, such as scleroderma ${ }^{34}$ and this finding has been postulated to have an important role in determining some lung function abnormalities. ${ }^{35} \mathrm{We}$. have no evidence that Raynaud's phenomenon of the lung was present in our patients. However, the fact that diffusion capacity was more impaired? among our SS patients with Raynaud's phenomenon? suggests that this mechanism might also contribute. to the lung damage in SS.

This study was supported by a grant from the "Ministero della Pubblica Istruzione'. We are indebted to Mrs Shona Cunninghamew Dryburgh for reviewing the English in the manuscript.

\section{References}

1 Moutsopoulos H M. Sjögren's syndrome (sicca syndrome) current issues. Ann Intern Med 1980; 92: 212-26.

2 Strimlan C V, Rosenow E C, 3rd, Divertie M B, Harrison E Jr. Pulmonary manifestations of Sjögren's syndrome. Ches 1976; 70: 354-61.

3 Newball H H, Brahim S A. Chronic obstructive airway disease in patients with Sjögren's syndrome. Am Rev Respir Dis 1977우 115: 295-304. 
4 Fairfax A J, Haslam P L, Pavia D, et al. Pulmonary disorders associated with Sjögren's syndrome. $Q J$ Med 1981; 50: 279-95.

5 Segal I, Fink G, Machtey I, Gura V, Spitzer S A. Pulmonary function abnormalities in Sjögren's syndrome and sicca complex. Thorax 1981; 36: 286-9.

6 Oxholm P, Bundgaard A, Birk Madsen E, Manthorpe R, Veijlø Rasmussen F. Pulmonary function in patients with primary Sjögren's syndrome. Rheumatol Int 1982; 2: 179-81.

7 Ropes M W, Bennett G A, Cobb S, et al. 1958 revision of diagnostic criteria for rheumatoid arthritis. Bull Rheum Dis 1958; 9: 175-6.

8 Tan E M, Cohen A S, Fries J F, et al. The 1982 revised criteria for the classification of systemic lupus erythematosus. Arthritis Rheum 1982; 25: 1271-7.

9 Masi A T, Rodnan G P, Medsger T A, et al. Preliminary criteria for the classification of systemic sclerosis (scleroderma). Arthritis Rheum 1980; 23: 581-90.

10 Sharp G C, Irvin W S, Tan E M, Gould R G, Holman H R. Mixed connective tissue disease: an apparently distinct rheumatic disease syndrome associated with a specific antibody to an extractable nuclear antigen (ENA). Am J Med 1972; 52: 148-59.

11 Bombardieri S, Paoletti P, Ferri C, DiMunno O, Fornai E, Giuntini C. Lung involvement in essential mixed cryoglobulinemia. Am J Med 1979; 66: 748-56.

12 Manca F, Migliorini P, Bombardieri S, Celada F. An enzymatically active antigen antibody probe to measure circulating immune complexes by competition. Clin Immunol Immunopathol 1980; 16: 131-41.

13 Kent J F, Fife E H Jr. Precise standardization of reagents for complement fixation. Am J Trop Med Hyg 1963; 12: 103-16.

14 Bunn C C, Gharavi A A, Hughes G R V. Antibodies to extractable nuclear antigens in 173 patients with DNA binding positive SLE: an association between antibodies to ribonucleoprotein and $\mathrm{Sm}$ antigens observed by counterimmunoelectrophoresis. J Clin Lab Immunol 1982; 8: 13-7.

15 Akizuki M, Boehm-Truitt M J, Kassan S S, Steinberg A D, Chused T M. Purification of an acidic nuclear protein antigen and demonstration of its antibodies in subsets of patients with sicca syndrome. J Immunol 1977; 119: 932-8.

16 Ogilvie C M, Forster R E, Blakemore W S, Morton J W. A standardized breath-holding technique for the clinical measurement of the diffusing capacity of the lung for carbon monoxide. J Clin Invest 1957; 36: 1-17.

17 Cotes J E, Hall A M. The transfer factor for the lung: normal values in adult. In: Arcangeli P, Cotes J E, Cournand A, et al., eds. Introduction to the definition of normal values for respiratory function in man. Torino: Panminerva Medica, 1970: $327-43$.

18 Bates D V, MacKlem P T, Christie R V. Respiratory function in disease. Philadelphia: Saunders, 1971.

19 Mastrangelo G, Chau N, Pham O T. Les différents modes d'expression du test au monoxide de carbon en régime stable: discussion et proposition de valeurs de référence pour les études épidémiologiques. Respiration 1980; 39: 28-38.
20 Goldman H I, Becklake M R. Respiratory function tests: normal values at median altitudes and the prediction of normal results Am Rev Respir Dis 1959; 79: 457-67.

21 Morris J F, Koski A, Breese J D. Normal values and evaluation of forced end-expiratory flow. Am Rev Respir Dis 1975; 111: 755-62.

22 Knudson R J, Slatin R C, Lebowitz M D, Burrows B. The maximal expiratory flow-volume curve. Normal standards, variability, and effects of age. Am Rev Respir Dis 1976; 113: 587-600.

23 Van Ganse W F, Ferris B G Jr, Cotes J E. Cigarette smoking and pulmonary diffusing capacity (transfer factor). Am Rev Respir Dis 1972; 105: 30-41.

24 MacKlem P T, Thurlbeck W M, Fraser R G. Chronic obstructive disease of the small airways. Ann Intern Med 1971; 74: $167-77$.

25 Talbott J A, Calkins E. Pulmonary involvement in rheumatoid arthritis. JAMA 1964; 189: 911-3.

26 Israel $\mathrm{H} \mathrm{C}$. The pulmonary manifestations of disseminated lupus erythematosus. Am J Med Sci 1953; 226: 387-92.

27 Weaver L, Divertie M B, Titus J L. The lung in scleroderma. Proc Mayo Clin 1967; 42: 754-66.

28 Constantopoulos S H, Acriditis N K, Dolevanga Y A, Moutsopoulos H M. Respiratory involvement in autoimmune rheumatic diseases is frequent and easy to detect. Clin Exp Rheumatol 1983; 1: 233-6.

29 Brentjens J R, O'Connell D W, Pawlowski I B, Hsu K C, Andres G A. Experimental immune complex disease of the lung. The pathogenesis of a laboratory model resembling certain human interstitial lung diseases. $J$ Exp Med 1974; 140: 105-25.

30 Yeo P B, Sinniah R. Lupus cor pulmonare with electron microscope and immunofluorescent antibody studies. Ann Rheum Dis 1975; 34: 457-60.

31 Lawley T, Moutsopoulos H M, Kats S I, Theofilopoulos A N, Chused T M. Demonstration of circulating immune complexes in Sjögren's syndrome. J Immunol 1979; 123: 1382-7.

32 Migliorini P, Riente L, Manca F, Celada F, Bombardieri S. Cold-precipitable immune complexes in collagen diseases: evidence for the coexistence of multiple types of circulating complexes in human serum. Clin Immunol Immunopathol 1983; 29: $129-40$.

33 Migliorini P, Aiuti F, Balestrieri G, et al. Comparison of pathological and normal sera by immune complex determination: five disease groups within 190 samples are discriminated by computer-selected combinations of 13 methods. Report of the Italian committee for the study of immune complexes (WIC). Clin Immunol Immunopathol 1984; 32: 298-315.

34 Naslund A J, Pearson T A, Ritter J M. A documented episode of pulmonary vasoconstriction in systemic sclerosis. John Hopkins Med J 1981; 148: 78-80.

35 Wise R A, Wigley F, Newball H M, Stevens M B. The effect of cold exposure on diffusing capacity in patients with Raynaud's phenomenon. Chest 1982; 81: 695-8. 